\title{
Monitoring Dissolved Oxygen Concentration (DOC) in Prawn Aquiculture Water Environment Based on Biological Behavior Characteristics
}

\author{
Haiqing Yang ${ }^{1, *}$, Jingbo Cai ${ }^{2}$, Guoquan Zeng ${ }^{2}$ and Hongxi $\mathrm{Wu}^{2}$
}

${ }^{1}$ College of Information Engineering, Zhejiang University of Technology, Hangzhou 310032, P.R.China

\author{
${ }^{2}$ Zhejiang Mariculture Research Institute, Wenzhou 325005, P.R.China \\ *Corresponding author, email: yanghq@zjut.edu.cn
}

Keywords: Prawn, aquiculture, biological behavior characteristics, dissolved oxygen concentration (DOC).

\begin{abstract}
Biological early warning system using physiological and behavioral responses of living organisms to water quality has been given much attention during past years. This study applied a digital video recording system to monitor prawn behavior under different water quality parameters. Three groups of prawn were used for calibration set while one group was for the validation of calibration results. A special water container was built for this experiment. The targeted water quality parameters, e.g. water salinity, $\mathrm{pH}$ and dissolved oxygen concentration (DOC), were adjusted by adding different chemicals in the water container. The calibration result shows that water salinity and $\mathrm{pH}$ have no significant impact on prawn behavior while changing DOC in water makes great influence on moving speed of prawns. When DOC is above $3.0 \mathrm{mg} / 1$, prawns move about 80 pixels $/ \mathrm{s}$; when DOC is between 2.6 and $1.74 \mathrm{mg} / \mathrm{l}$, prawns move at 120 pixels/s; and when DOC is below 1.2 $\mathrm{mg} / \mathrm{l}$, prawns move up to $1000-1200$ pixels/s. The validation set of prawns under changing DOC from 1.82 to $0.54 \mathrm{mg} / \mathrm{l}$ confirms the calibration results. This proposed method is worthy of being further investigated for practically monitoring aquiculture environment.
\end{abstract}

\section{Introduction}

Recent advances in communication and sensor technology have catalyzed progress in monitoring capabilities for water quality[1]. Li et al.[2] introduced a knowledge-based early warning system for fish disease via water quality management. The review by Storey et al.[3] presented the findings of an international study on monitoring drinking water quality in Europe, the United States and Singapore involved in the development and deployment of on-line monitoring technology for the detection of contaminants in water.

Many biological early warning systems (BEWS) have been developed in recent years that evaluate the physiological and behavioral responses of whole organisms to water quality. Thomas et al.[4] proposed an early warning system for monitoring the quality of water using the information conveyed by the continuous electric organ discharges of the tropical fish Apteronotus albifron. Van der Schalie et al.[5] introduced an operation of a BEWS at a groundwater treatment facility using a fish ventilator monitoring system developed at the US Army centre for Environmental Health Research. Lzydorczyk et al.[6] developed an early warning method for the detection of cyanobacterial biovolume in the source water in order to establish an alert level framework for the drinking water abstraction point in Sulejow Reservoir, Poland. Lee et al.[7] developed a remotely controlled autonomous real time field monitoring system to continuously track the changes in chlorophyll fluorescence, dissolved oxygen and other hydrometeorological variables at two representative mariculture zones around Hong Kong. Tahedl and Hader[8] developed an early warning system called ECOTOX for monitoring the quality of water using different movement parameters of the motile unicellular flagellate Euglena gracilis as end points. Jeon et al.[9] developed a BEWS equipped with six monitoring channels to individually observe the activity of Daphnia magna, using a digital Grid Counter, which would trigger an alarm within an appropriate time, and examine the functional performance of the BEWS for detecting unusual water quality. Kim et al.[10] developed an 
early-warning biosensor system based on the swimming behavior of Japanese medaka (oryzias latipes) as an indicator of indoor air chemical compounds which was dissolved into water. To our knowledge, no published studies have addressed the monitoring of water quality in prawn aquiculture using biological behavior characteristics.

The objective of this study is to use a digital video recording system to monitor and evaluate sea water aquiculture environment based on prawn behavior under different water quality parameters.

\section{Materials and Methods}

Experimental water container. Due to the semi-transparency of prawn body, traditional water container with deep water makes bad observation. Therefore, a special experimental glass water container was created with sizes of $50 \mathrm{~cm}$ long, $40 \mathrm{~cm}$ high and $6 \mathrm{~cm}$ wide for crystal video recording. Prawn samples and water parameters adjustment. Prawns with uniform body length of 2-3 cm were selected from a local species of South American white prawn (Nan-mei Bai-dui-xia). Four groups of prawn were established for calibration and validation. Of them, groups 1, 2 and 3 were used for calibration while group 4 was for validation (Table 1). Water salinity, $\mathrm{pH}$ and DOC in the experimental water container were adjusted by adding $\mathrm{NaCl}, \mathrm{NaOH} / \mathrm{HCl}$ and $\mathrm{Na}_{2} \mathrm{~S}_{2} \mathrm{O}_{4}$, respectively.

Table 1 Prawn groups for calibration and validation of water quality prediction

\begin{tabular}{ccccccc}
\hline Group & Group & Prawn number & DOC $(\mathrm{mg} / \mathrm{l})$ & Water salinity & $\mathrm{pH}$ & Temperature $\left({ }^{\circ} \mathrm{C}\right)$ \\
\hline Calibration & $\# 1$ & 4 & $10-3.0$ & $0.5-9.6$ & $5.0-9.5$ & $20-25$ \\
& $\# 2$ & 4 & $2.6-1.74$ & $0.5-9.6$ & $5.0-9.5$ & $20-25$ \\
& $\# 3$ & 5 & $1.18-0.72$ & $0.5-9.6$ & $5.0-9.5$ & $20-25$ \\
Validation & $\# 4$ & 5 & $1.82-0.54$ & $0.5-9.6$ & $5.0-9.5$ & $20-25$ \\
\hline
\end{tabular}

Water quality instruments. YSI-5200 Multi-probe handheld multi-parameter instrument and YSI-DO200 meter were used for water quality reference measurement.

Digital video recording system. Figure 1 illustrates the components of experimental system. It consists of a high-resolution digital video recorder, a USB communication cable and a laptop computer. The video frames recorded with an interval of $1 \mathrm{~s}$ were processed by Matlab software.

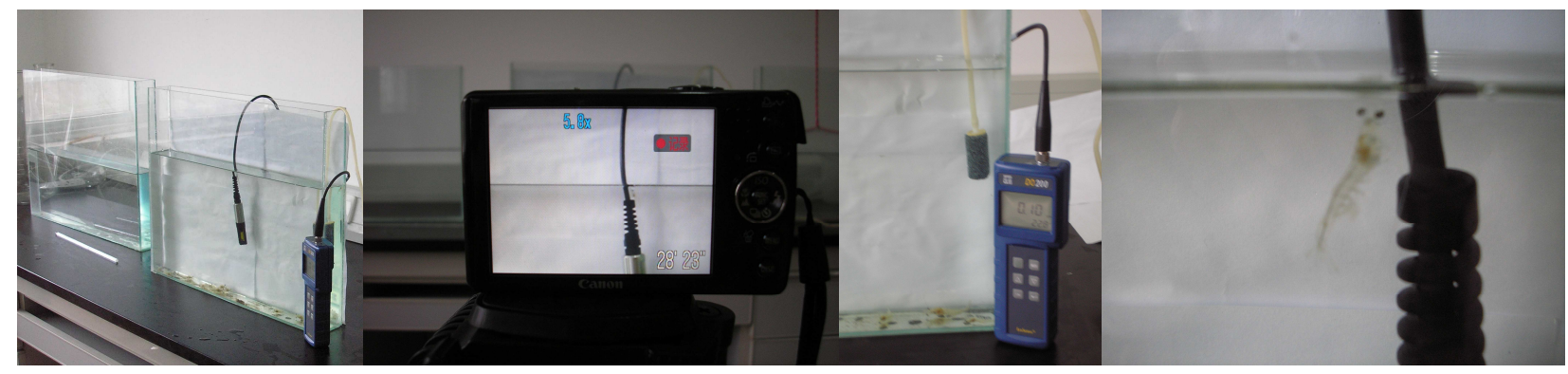

Fig.1 Experimental water container, DVR, DO meter and prawn samples

\section{Results and Discussion}

Effect of water salinity and pH to prawn activity. It was observed that water salinity changing from fresh water to normal sea water has no significant effect on prawn activity. Also, the impact of changing PH from 5.0 to 9.5 on prawn behavior was unnoticeable. This may explain that the prawn species under investigation is widely cultivated due to its strong tolerance to aquiculture environment. Thus, we just concerned about the influence of water DOC on prawn behavior in further examination. Parameterization of prawn behaviors in water container. Restricted by the special design of experimental water container, prawns movement can be depicted by 2-dimension coordinates. In order to simplify the parameterization of prawn positions, we regarded a prawn as a point in this $2 \mathrm{D}$ 
reference plane. It is interesting that a prawn in video frames can be clearly distinguished by the dark feces in its body. The center of dark feces was then digitalized to $\mathrm{X}$ and $\mathrm{Y}$ coordinates in pixels, which can be used for positioning the prawn in water container. The time sequence of these X-Y pair values constitutes the moving track of prawns in water, which allows calculating moving speed of prawns in pixels per second.

Figure 2 illustrates the changes of moving speed of 4 prawns in group 1 under DOC $>3.0 \mathrm{mg} / \mathrm{l}$. The maximum moving speed is 80 pixels/s. Figure 3 shows the relevant moving speed of 4 prawns in group 2 under DOC values between 2.6 and $1.74 \mathrm{mg} / \mathrm{l}$. The maximal speed is about 120 pixels/s. However, when water DOC decreased under $1.2 \mathrm{mg} / 1$, prawns in group 3 tended to swim with dysphasia and move upwards (Fig. 4). The maximum speed increased dramatically to 1000-1200 pixels/s. This may explain that DOC of $1.2 \mathrm{mg} / 1$ is the minimal tolerance of DOC in water for prawns.

Figure 5 illustrated the moving speeds of prawns in validation group 4. It is observed that moving speed changes with DOC. When DOC is above $1.6 \mathrm{mg} / 1$, prawns move at less than 200 pixels/s. By contrast, when DOC is between 1.6 and 1.4, prawns move faster up to 900-1200 pixels/s. When DOC is below 1.4, prawns move at more than 1600 pixels/s. These validation results are in line with the ones in calibration groups 1,2 and 3. Figure 6 illustrated the position sequence of prawn $\# 1$ in the validation group subjected to $\mathrm{DOC}=1.82-1.60$ and $\mathrm{DOC}=1.40-0.54$.

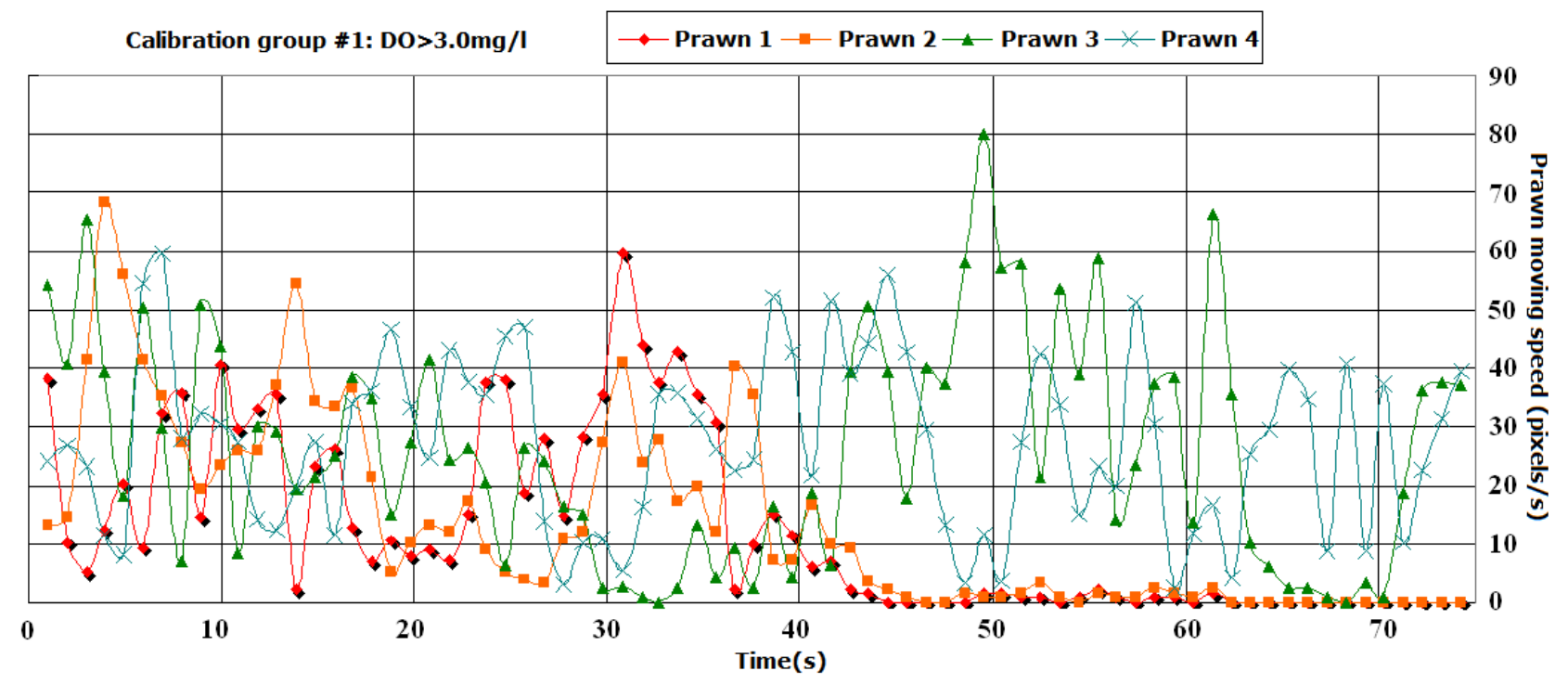

Fig.2 Calibration group 1 with 4 prawns (DO $>3.0 \mathrm{mg} / \mathrm{l})$

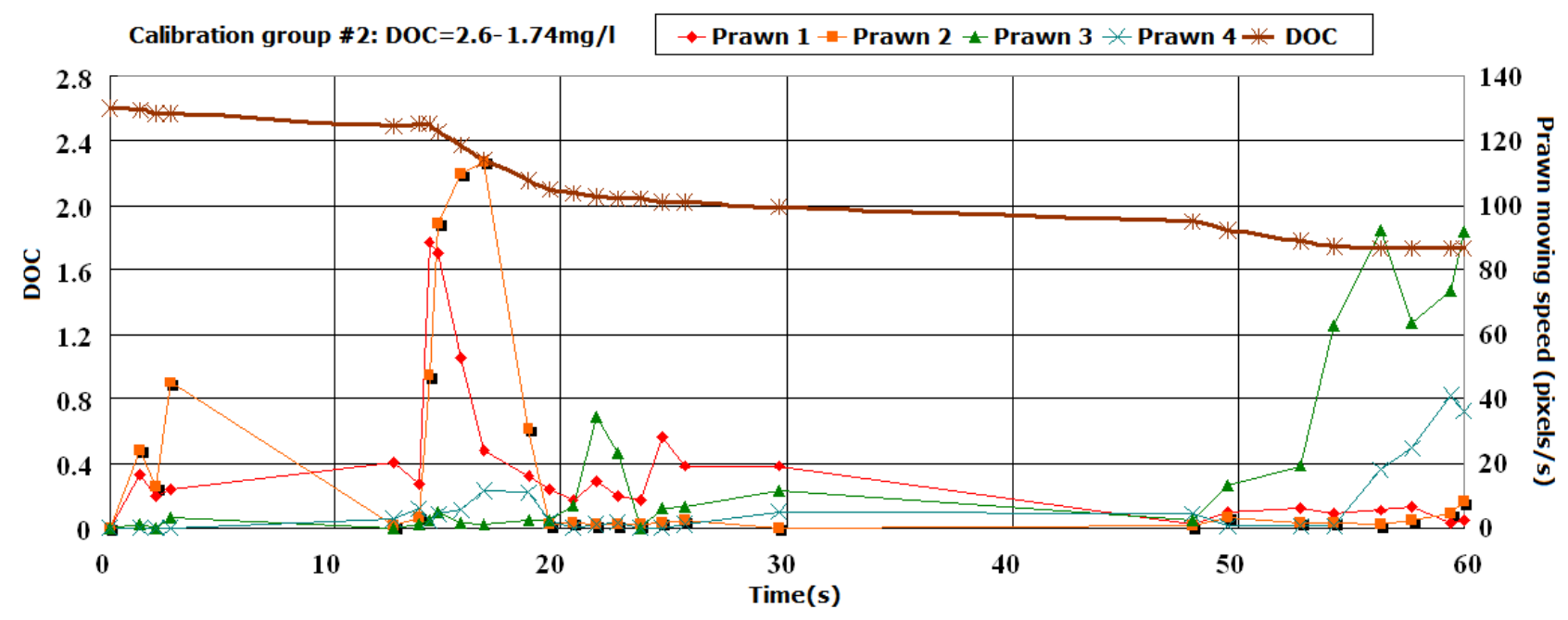

Fig.3 Calibration group 2 with 4 prawns $(1.74 \mathrm{mg} / 1<$ DOC $<2.60 \mathrm{mg} / \mathrm{l})$ 


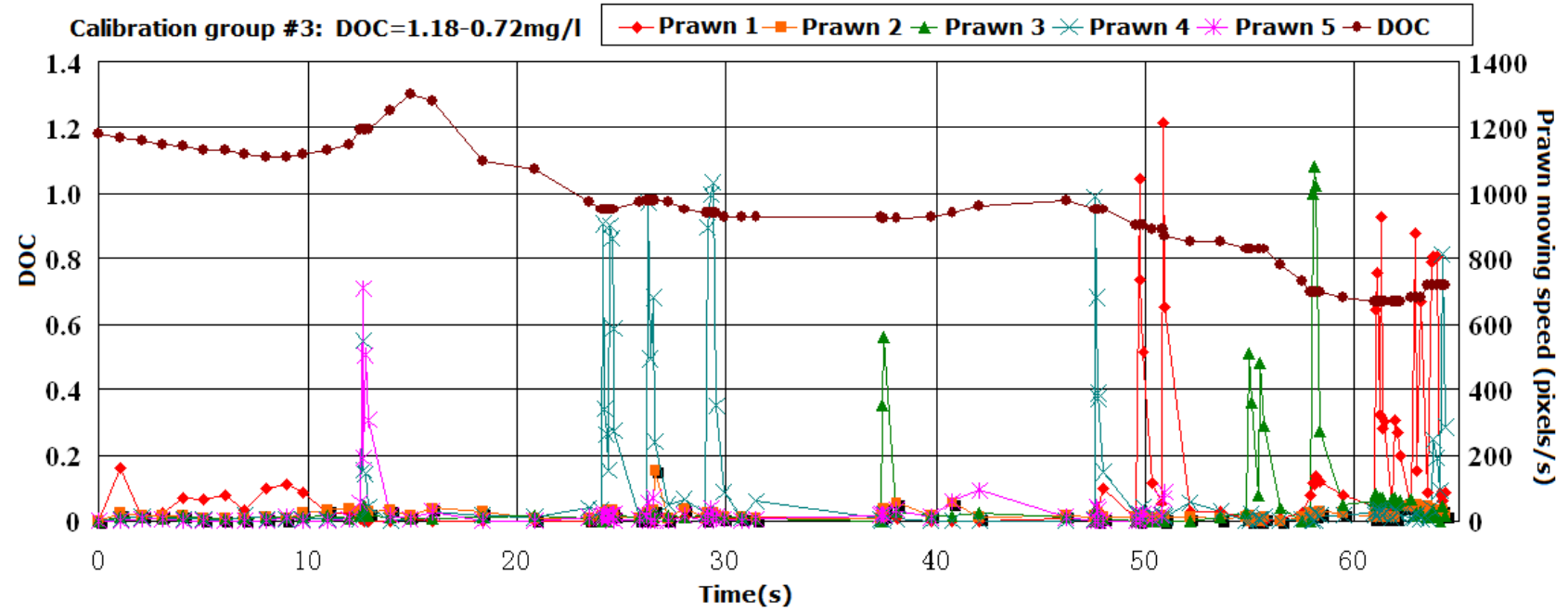

Fig.4 Calibration group 3 with 5 prawns $(\mathrm{DOC}<1.4 \mathrm{mg} / \mathrm{l})$

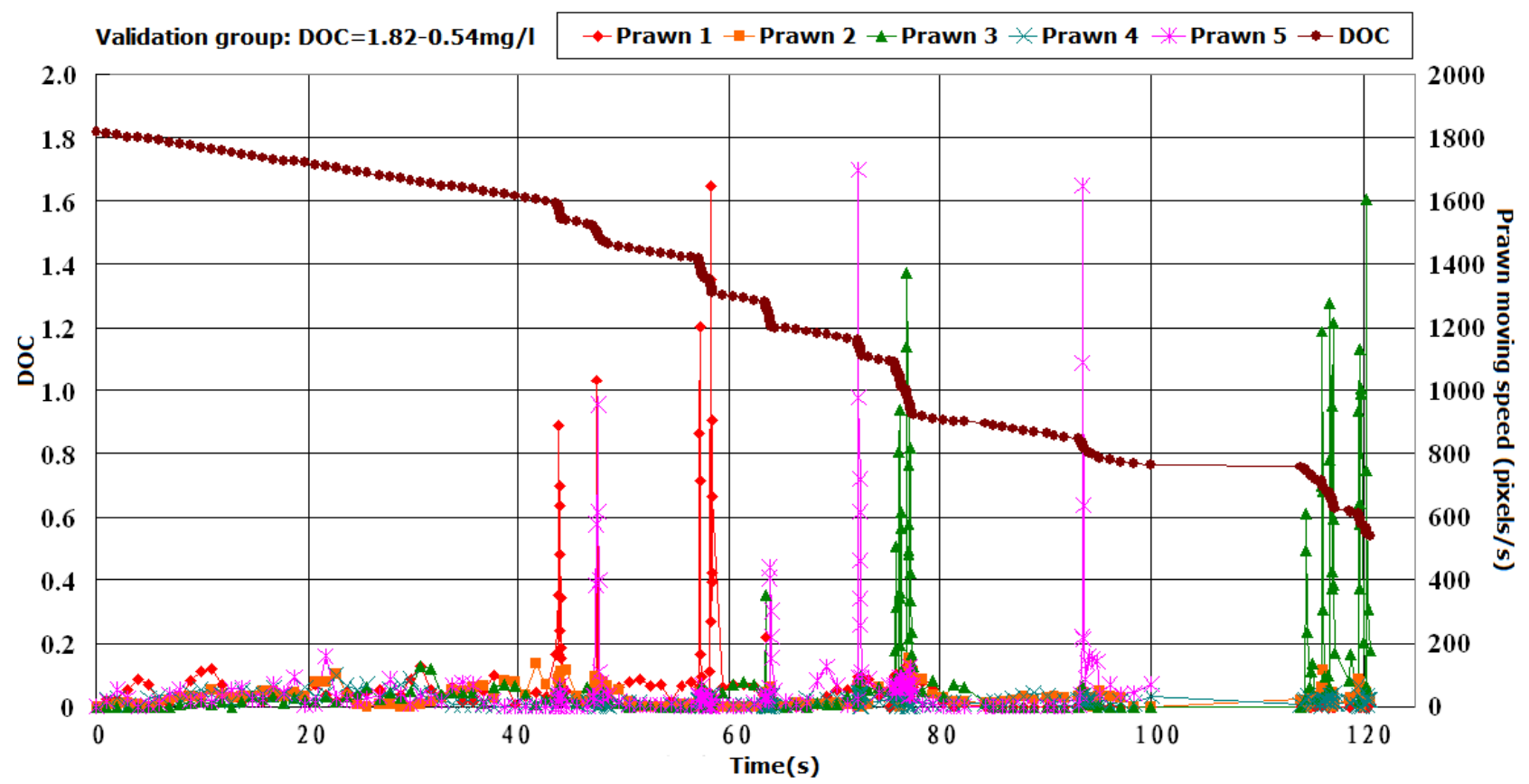

Fig. 5 Validation group with 5 prawns (DOC changing from $1.82 \mathrm{mg} / 1$ to $0.54 \mathrm{mg} / \mathrm{l}$ ) 


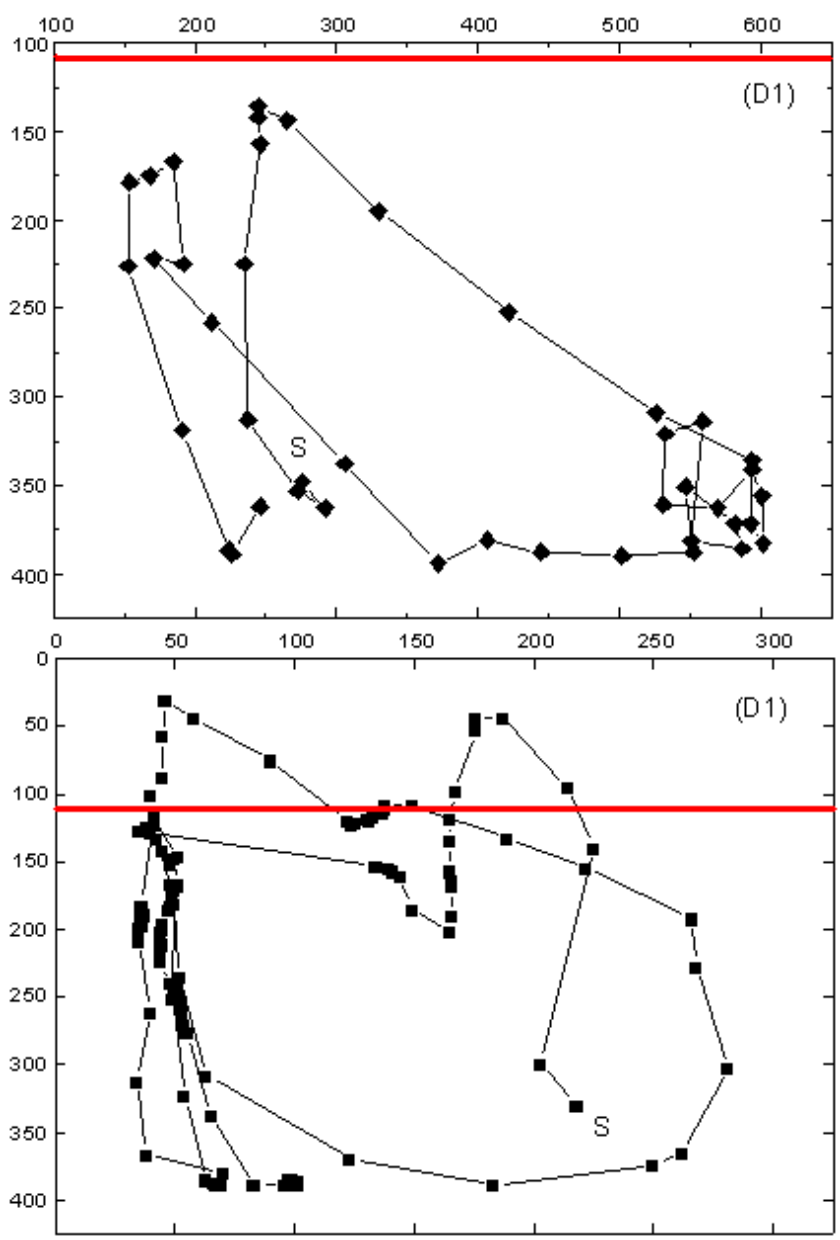

Fig. 6 Position sequence of prawn $\# 1$ in validation group subjected to $\mathrm{DOC}=1.82-1.60 \mathrm{mg} / 1$ (left) and $\mathrm{DOC}=1.40-0.54 \mathrm{mg} / \mathrm{l}$ (right), respectively. Red line: water/air interface.

\section{Conclusions}

This study applied a digital video recording system to monitoring prawn behavior under different water quality parameters. Three groups of prawn were used for calibration set while one group was for the validation of calibration results. A special water container was built for this experiment. The targeted water quality parameters, e.g. water salinity, $\mathrm{pH}$ and dissolved oxygen concentration (DOC), were adjusted by adding different chemicals in the water container. The calibration result shows that water salinity and $\mathrm{pH}$ have no significant impact on prawn behavior while the moving speed of prawns are strongly affected by changing DOC in water. When DOC is above $3.0 \mathrm{mg} / \mathrm{l}$, prawn moving speed is about 80 pixels/s; when DOC is between 2.6 and $1.74 \mathrm{mg} / \mathrm{l}$, prawn moves at 120 pixels/s; and when DOC is below $1.2 \mathrm{mg} / \mathrm{l}$, prawn moving speed fastens up to $1000-1200$ pixels/s. The validation set of prawns under changing DOC from 1.82 to $0.54 \mathrm{mg} / \mathrm{l}$ confirms the calibration results. This proposed method is worthy of being further investigated for practically monitoring aquiculture environment.

\section{Acknowledgements}

The authors gratefully thank the Mariculture Station at Yong-xin, Wenzhou city, P.R.China for the provision of prawn samples. This study was financially supported by the Open Project Foundation of Zhejiang Key Lab of Exploitation and Preservation of Coastal Bio-resource (No. 2010F30003J2010007). 


\section{References}

[1] H.B. Glasgow, J.M. Burkholder, R.E. Reed, A.J. Lewitus, J.E. Kleinman, Real-time remote monitoring of water quality: a review of current applications, and advancements in sensor, telemetry, and computing technologies, Journal of Experimental Marine Biology and Ecology. 300(2004)409-448.

[2] N. Li, R. Wang, J. Zhang, Z. Fu and X. Zhang, Developing a knowledge-based early warning system for fish disease/health via water quality management, Expert Systems with Applications. 36(2009)6500-6511.

[3] M.V. Storey, B. van der Gaag, B.P. Burns, Advances in on-line drinking water quality monitoring and early warning systems, Water Research. 45(2011)741-747.

[4] M. Thomas, A. Florion, D. Chretien, D. Terver, Real-time biomonitoring of water contamination by cyanide based on analysis of the continuous electric signal emitted by a tropical fishL Apteronotus albifrons, Water Research. 30(1996)3083-3091.

[5] W.H. van der Schalie, T.R. Shedd, P.L. Knechtges, M.W. Widder, Using higher organisms in biological early warning systems for real-time toxicity detection. Biosensors and Bioelectronics. $16(2001) 457-465$.

[6] K. Lzydorczyk, C. Carpentier, J. Mrowczynski, A. Wagennvoort, T. Jurczak, M. Tarczynska, Establishment of an alert level framework for cyanbacteria in drinking water resources by using the algae online analyzer for monitoring cyanobacterial chlorophyll $a$, Water Research. 43(2009)989-996.

[7] J.H.W. Lee, I.J. Hodgkiss, K.T.M. Wong, I.H.Y. Lam, Real time observation of coastal algal blooms by an early warning system, Estuarine, Coastal and Shelf Science. 65(2005)172-190.

[8] H. Tahedl and D. Hader. Fast examination of water quality using the automatic biotest ECOTOX based on the movement behavior of a freshwater flagellate, Water Research. 33(1999)426-432.

[9] J. Jeon, J.H. Kim, B.C. Lee, S.D. Kim, Development of a new biomonitoring method to detect the abnormal activity of Daphnia magna using automated Grid Counter device, Science of The Total Environment. 389(2008)545-556.

[10] J. Kim S. Kato, K. Takeuchi, T. Tatsuma, I.J. Kang, Evaluation on potential for assessing indoor formaldehyde using biosensor system based on swimming behavior of Japanese medaka (oryzias latipes), Building and Environment. 46 (2011)849-854. 